\title{
A Administração sob as Condições de Descentralização e de Participação dos Cidadãos
}

\author{
Adam W. Herbert \\ Da Universidade Estadual e Instituto Politécnico da Virgínia \\ Tradução de Vera D. G. Côrtes \\ Fonte: Public Administration Review, n. ${ }^{\circ}$ Especial, out. 1972
}

Durante a última década houve um aumento significativo dos pedidos e propostas em favor de uma maior descentralização governamental e de uma maior participação dos cidadãos na elaboração e execução das diretrizes do poder público. Os defensores de um ou outro aspecto dessas propostas são encontrados numa miríade de grupos e pessoas, que vão desde a Casa Branca, diversos líderes parlamentares * candidatos presidenciais, até grupos separatistas e do "Poder Negro", organizações conservadoras de brancos, numerosos intelectuais e entidades profissionais como o Social Welfare Workers Movement (Movimento de Assistentes Sociais) e o Teachers for Community Control (Professores Pró Controle Comunitário). Ante um apoio tão diversificado e aparentemente em exPansão, não é mais possivel que o,po- tencial para concretização de alguma espécie de participação mais formalizada dos cidadãos no processo de formulação de diretrizes governamentais seja ignorado pelos administradores públicos ou pelas escolas profissionais em que são treinados, nem tampouco podem ser ignoradas as implicações administrativas dessa participação.

É claro que será difícil predizer com exatidão o papel que os cidadãos realmente desempenharão ou o limite final de sua participação no processo de formulação de diretrizes governamentais. Não obstante, é necessário examinar os desafios administrativos em potencial decorrentes de diferentes graus de participação dos cidadãos e de descentralização administrativa. Deve-se fazer um esforço no sentido de 
prever alguns dos problemas, possibilidades, opções e beneficios que se poderão apresentar aos administradores públicos em decorrência do movimento em direção a uma maior participação dos cidadãos nos processos administrativos do governo. Este ensaio procura identificar e examinar algumas conseqüências possiveis da maior participação dos cidadãos na formulação de diretrizes oficiais e explorar a significação dessas novas orientações para escolas de administração pública.

Como seu título indica, esta análise está focalizada em descentralização administrativa e participação dos cidadãos. Descentralização administrativa se refere, de uma forma geral, à delegação de autoridade de niveis superiores para níveis inferiores dentro de uma organização. 11 Obviamente, descentralização não pressupöe nem implica participação dos cidadãos. Entretanto, os governos podem descentraiizar a fim de facilitar tal participação. $\mathrm{Na}$ verdade, como sugere Hallman, os governos descentralizam por duas razões: (a) para alcançar maior eficiência, ou (b) para estabelecer melhores relações com os cidadãos 16 (pág. 8). Preocupamo-nos aqui com a descentralização nesse último sentido. Especificamente, usando a concepção de Eisinger de partilha de controle, nos referimos às implicações administrativas da descentralização de "órgãos municipais nos quais a autoridade para tomar decisões sobre diretrizes referentes a niveis de serviço e padrões administrativos gerais é partilhada por burocratas profissionais, ocupantes de cargos eletivos $\theta$ representantes dos

R. Serv. públ., Brasilia, 108 (3) set./dez. 1973 cidadãos de áreas (distritos*) ou grupos determinados" 78, (pág. 38). Essa orientação aparece com a maior clareza quando se consideram os quatro niveis possiveis de descentralização identificados por Hallman: 1 controle central absoluto sobre tomada de decisões dentro do programa do distrito; ${ }^{2}$ controle, misto, com predominância do centro; 3 controle misto, com predominância do distrito; e 4 controle efetivo total no nível distrital 16 (pág. 21). Este ensaio focaliza essencialmente o segundo e o terceiro níveis tais como descritos acima. A decisão de focalizar o segundo e o terceiro niveis está baseada no julgamento de valor de que é necessária uma mudança do sistema primordial contemporâneo de prestação de serviço público - Nível 1. ou Modelo de Intercâmbio de Schmandt 125 - e na crença de que a implementação da etapa quatro está longe demais, na maioria das cidades com população superior a $50.000 \mathrm{habi-}$ tantes, para ser diretamente objeto de nossas preocupações imediatas.

Foi preparada uma relação de obras recentes que poderiam ser úteis a $a d$ ministradores públicos para compreenderem o fenômeno da participação dos cidadãos e questões correlatas. Conquanto várias referências não sejam feitas neste trabalho, as obras foram incluídas na relação para fins de $e^{-}$ tabelecimento de currículos, a fim de servir de útil ponto de partida para a implementação de algumas das ori-

- o termo distrito é usado nesta traduçăo em lugar de "neighborhood"; poderiam ser igualmente usados os termos bairro, vizinhança e outros análogos, mas o importante é considerar que com ele o autor se refere de a uma área administrativa especifica, tamanho urbano limitado. (N.T.) 
entações didáticas aqui mencionadas o para o estudo em profundidade do processo de participação. Não se faz aqui qualquer tentativa de examinar ou resumir os muitos argumentos apresentados nessas obras em apoio do conceito de participação dos cidadãos; isso foi feito, com muita eficiência, em outra parte deste simpósio. O presente ensaio parte da premissa de que a ampliação de tal participação na formulação de diretrizes governamentais é essencial, se não inevitável, e tentou-se nele aquilatar as implicações dessa circunstância sob uma perspectiva administrativa. São os seguintes os argumentos básicos em torno dos quais foi elaborado este ensaio:

- A participação dos cidadãos nos aspectos administrativos dos negócios públicos pode ser essencial para neutralizar os sentimentos de irremediabilidade, frustração, impotência e amargura que se tornam cada vez mais evidentes nos $\begin{array}{llllll}\text { Estados Unidos. } & 2 & 9 & 10 & 19 & 27\end{array}$ $45 \quad 52 \quad 57$

- Para que se possa dar respostas adequadas às necessidades sociais que se estão expandindo rapidamente, é preciso desafiar os valores e crenças administrativos tradicionais a respeito de eficiência e da necessidade de hierarquia.

Conquanto a eficiência tenha de continuar sendo uma variável importante na determinação das diretrizes governamentais, é agora necessário definir eficiência de for$\mathrm{ma}$ tal que se incorpore mais plenamente na definição a percepção que têm os cidadãos da eficácia dos programas.

- Os incômodos pessoais e profissionais que a maior participação dos cidadãos pode causar para os administradores públicos, funcionários do governo e os próprios cidadãos participantes são preços que se tem de pagar na busca de um governo mais receptivo e mais eficiente.

- O maior desafio aos administradores públicos que estejam trabaIhando dentro de um esquema de participação residirá na identificação e equilibrio das necessidades e exigências dos cidadãos em relação às necessidades e exigências sócio-emocionais, potencialmente conflitantes, dos servidores públicos, ocupantes de cargos eletivos e superiores administrativos.

- As escolas de administração pública deveriam começar imediatamente a efetuar as modificações necessárias para assegurar que seus currículos produzirão formandos capazes de operar dentro de esquemas de participação.

Perspectivas para a Sociedade e a Burocracia norte-americanas

Em uma nação democrática, pareceriam à primeira vista desnecessários os debates sobre a factibilidade e a utilidade da participaçăo dos cidadãos na formulaçăo de diretrizes governamentais, pois é claro que muitos cidadãos - individualmente ou em grupos de pressão - têm participado 
consistentemente do processo governamental norte-americano em todos os niveis. 40 Assim, por exemplo, as pessoas indicadas para funções administrativas ou comissões importantes são freqüentemente alvo de avaliação por muitos dos grupos cujos interesses ou bem-estar poderão afetar servindo naquelas posições. Além disso, ocasionalmente se solicita o conselho de grupos interessados ou indivíduos selecionados (inclusive consultores) com respeito ao desenvolvimento de programas ou formas de operação e ao estabelecimento de novas provisões regulamentadoras governamentais. De quando em vez são também realizadas audiências públicas de maneira a possibilitar aos cidadãos manifestar suas reações ou críticas a atividades governamentais.

Essas formas de participação, ou outras semelhantes, servem apenas para tornar menos clara a questão da participação. Elas não indicam quem são os grupos e individuos participantes ou quem não está autorizado a participar. Elas não refletem as restrições impostas à participação nem indicam a amplitude ou alcance real que se procura conseguir para essas contribuições. $\mathrm{Na}$ verdade, embora alguns possam argumentar que a participação dos cidadãos é um aspecto já firmado da administração pública, tanto na teoria como na prática, temse evitado de forma consistente e sistemática a democracia participativa quando relacionada com operações burocráticas governamentais, 53 exceto nos casos em que a cooperação ou o apoio do grupo interessado era essencial para favorecer os interesses do órgão em pauta. $48 \mathrm{Em}$ pouquíssimos casos os administradores públicos aceitaram de bom grado o conceito de que os cidadãos deveriam ter voz significativa nas atividades administrativas do governo.

É indiscutível a ênfase historicamente dada à participação dos cidadãos nos assuntos políticos e legislativos, por contraposição aos assuntos administrativos. Inicialmente, a nação era controlada em virtualmente quase todos os aspectos por uma oligarquia de ricos proprietários. Esse controle foi sendo gradualmente erodido à medida em que o princípio do "governo pelo homem do povo" se concretizava nos níveis local, estadual e nacional. Simultaneamente, a luta em favor da extensão do direito de votar e ser votado a outras pessoas além dos proprietários do sexo masculino e de cor branca teve êxito e prosseguiu na década dos 70. Também de importância especial, sob o ponto de vista histórico, foi - movimento no sentido de aumentar a participação dos cidadãos no processo legislativo de governo, através do emprego de instrumentos como iniciativa popular, referendum, destituiçăo pelos_eleitores de autoridades eleitas e o preenchimento de grande número de cargos administrativos por eleição popular. O cidadão estava assim capacitado a fazer e revogar leis, a eleger a maioria das autoridades públicas e a declará-las impedidas.

No pensamento de muitos reformadores governamentais, começando nos fins do século passado e estendendose até a década de 1940 , essa ampla participação dos cidadãos em assun- 
tos governamentais levou a "máquinas" políticas, ineficiência e governos orientados para interesses especiais (essencialmente de imigrantes e moradores urbanos de baixo nivel de renda). A reação a essas "deficiênclas" se manifestou sob a forma de esforços para fortalecer o presidente, reduzir o número de cargos administrativos eletivos, exigir promoções por merecimento e nomeações através de exames objetivos, reduzir o número de autoridades eleitas e ampliar a ênfase na eficiência das operações governamentais 12,61 . A fundamentação para essas "reformas" parecia ser a de que a manutenção de um governo eficiento só poderia ser garantida através de uma mudança para formas ou procedimentos governamentais que criassem oportunidades para que os cidadãos "com espírito público" pudessem administrar os negócios do governo. 60 Ironicamente, poucos levantaram dúVidas sobre o fato de que essas modificações na verdade serviam aos interesses dos cidadãos "com espírito Público", que tomaram o controle goVernamental até então exercido por aquelas máquinas políticas que cortelavam os moradores urbanos de baixo nivel de renda supostamente "com esPirito egoista". 62

Desde a implementação dessas "reformas" politicas e administrativas, os administradores ficaram ainda mais isolados da participação formal dos cidadãos em suas atividades, $31 \mathrm{ex}$ coto quando a participação sob alguma forma era considerada como sendo do interesse do administrador. 0 profissionalismo atingiu um nível de preominência que atualmente rivaliza com
- interesse público. 80 profissional sabe o que melhor atende aos interess ses do cidadão. Seu treinamento e experiência, combinados com novas tecnologias administrativas e técnicas de análise, the dão uma visão e uma perspectiva que supostamente transcendem os interesses de grupos determinados na busca do "bem comum". 22 Como resultado, não há necessidade alguma, dizem-nos, de permitir que cidadãos desinformados, orientados egoisticamente e com uma visão míope das questões se tornem obstáculos ao funcionamento eficiente e bem sucedido do governo. Quando os cidadãos votam, eles agem no nivel de participação correspondente à frase "governo pelo povo"; quando se necessitar dos cidadãos por alguma outra forma, eles serão chamados.

O atual impulso no sentido da participação dos cidadãos nos assuntos administrativos do governo deve conseqüentemente ser considerado como um afastamento importante das concepções tradicionais do papel apropriado dos cidadãos no processo governamental. 53 Embora tenhamos aceito, como indicado acima, a idéia de que autoridades eleitas e programas governamentais devem ser submetidos ao exame e à aprovação do público, o administrador tem sido excluído dessa prestação de contas obrigatória. A importância do movimento pela participação pode ser a de que ele representa uma tentativa de fechar o círculo de receptividade governamental. Ele abrange a idéia de que, tal como as autoridades eleitas e os programas governamentais em geral, os administradores profissionais não mais estão 
acima das vozes e exigências do povo. Ele representa um esforço para equilibrar melhor a eficiência e a especialização administrativas com os sentimentos, desejos e necessidades perceptiveis dos cidadăos à medida em que os programas oficiais vão sendo executados.

\section{Administração Pública: Avaliação de Ideologia e Direção}

Em um número recente da "Public Administration Review, Thomas W. Fletcher, então administrador da cidade de San Jose, Califórnia, observou que:

"A participação dos cidadãos chegou para ficar. Temos de reconhecer que isso significa que de agora em diante temos de partilhar as decisões importantes que tomamos na medida em que afetam as vidas de todas as pessoas que vivem em nossa comunidade. $E$ uma vez que encaremos realisticamente esse problema e provemos aos cidadãos e a nós mesmos que estamos falando sério, serão eliminadas as confrontações que constituem um começo natural desse processo" 163 (pg. 16).

Embora tal orientação administrativa pareça agora especialmente apropriada, é significativo que muitos administradores profissionais continuam a se aferrar firmemente às teorias mais tradicionais de organização administrativa e prática burocrática. Essas teorias tradicionais, que ressaltam o que Redford denominou de "democracia por cima", 34 estão baseadas em quatro conceitos essenciais: (a) integração - as unidades da administra- ção deveriam estar vinculadas numa linha única de responsabilidade que sobe até o chefe principal; (b) hierarquia - a responsabilidade seria imposta pelo uso do poder através dos sucessivos niveis, cada um controlando o nivel imediatamente inferior; (c) legalidade - as normas estabelecidas nos niveis superiores da hierarquia orientariam a ação dos indivíduos em todos os níveis subordinados; $e$ (d) supremacia politica - a administração deveria estar subordinada à direção e supervisão políticas, exercidas através da lei e da supervisão hierárquica. ${ }^{34}$ (pg. 7 ).

Essa caracterização das operaçōes burocráticas oficiais omite muitos dos inconvenientes das operações governamentais tais como descritos por Pfiffner e Sherwood em seu conceito de "revestimentos" 36 (pgs. 16-32). Năo obstante, ela identifica muito da sabedoria convencional que continua a guiar o pensamento de um grande número de administradores. Ela ressalta em especial os principios de que: (a) as diretrizes deveriam ser es. $^{-}$ tabelecidas no topo da estrutura institucional hierárquica e transmitidas para baixo; e (b) os administradores estão subordinados a autoridades eleitas que têm a responsabilidade de estabelecer as diretrizes. Um terceiro princípio de considerável importância, embora não identificado explicitamente acima, é o da necessidade da obediência burocrática a padrōes de eficiência, neutralidade e economia na prestação de serviços públicos.

Embora essa sabedoria convencional tenha sido posta em dúvida por 
diversos autores de obras sobre administração de empresas - McGregor 110 Argyris, 65 Likert 104 e Bennis 3 - os administradores públicos, de uma forma geral, não se impressionaram com os argumentos dos que criticam a hierarquia e a eficiência. Wilcox, por exemplo, retrucou que:

"Os pensadores "participativos" rejeitam as medidas tradicionais de eficácia, economia e eficiência como irrelevantes para a avaliação de organizações. Eles consideram a consecução dos valores desejados nas relações entre as pessoas como a única medida pertinente. Porém é a eficácia relativa das organizaৎ̧ões, medida em termos convencionais e em proporções de insumoprodução que influenciam fortemente a qualidade da reação de uma sociedade aos desafios da mudança". 59 (pg. 62).

Conquanto tal atitude possa ser utilizada como forma de fuga temporária à realidade de que as principais mudanças administrativas no sentido de uma participação maior são altamento necessárias, e talvez inevitáveis, ela não toca nos argumentos que são de fato apresentados pelos pensadores Participativos.

Os propugnadores da administração Participativa estão perfeitamente cônscios da necessidade de eficiência e liderança administrativa nas operações burocráticas e não objetam a elas Per se. O que procuram é encorajar uma administraçăo mais humana $e$ uma definição mais precisa e realista de eficiência e finalidade organizacio- nal 3. Eles se perturbam com 0 fato de que a eficiência tem sido usada como um biombo por trás do qual os administradores muitas vezes se recusam a lidar com problemas importantes ou considerar as implicações humanas de suas diretrizes. White ilustra esse ponto com seu exemplo de que "se o cliente parece necessitar de mais recursos ou "insumo" para c tratamento do que a solução do seu caso representa como unidade de "produção" da organização, ele simplesmente não será tratado. Tratá-lo seria "ineficiente" 58 (pg. 36). Os pensadores participativos dizem que a eficiência precisa ser definida não apenas em termos de produção por chefes "neutros", mas também pela forma como o servidor e a clientela vêem tanto as necessidades como a produção. Como isso não foi feito antes, a eficácia relativa de muitos órgãos oficiais em áreas sociais tem sido tão pequena que agora são necessárias medidas corretivas urgentes tais como a participação dos cidadãos. 46

\section{A Nova Administração Pública}

Os opositores mais articulados da ideollogia tradicionalmente autoritária de administração pública se encontram num grupo dentro da profissåo que começou a desafiar aqueles valores sob o rótulo de "Nova Administração Pública". 146157 Eles argumentam que "as atuais tensões sociais indicam a necessidade de uma "correção a meio-caminho" nas normas de administração pública, uma correção destinada a aumentar a capacidade do governo de satisfazer as necessidades de todos os cidadãos. $\mathrm{A}$ eqüidade so- 
cial é a correção a meio-caminho que se requer, basicamente porque a desigualdade é uma das características sociais, econômicas e políticas mais cruciais de nossa época". ${ }^{141}$ (pg. 2). Frederickson 141 (pg. 3) identificou os seguintes requisitos como sendo os ingredientes essenciais da ética da eqüidade:

- o reconhecimento de que a neutralidade administrativa de valores é improvável, talvez impossível e certamente não desejável;

- um serviço público é um bem público geral que comumente pode ser bem ou mal executado;

- independentemente de quão bem ou mal são executados, os serviços públicos prestados de forma geral variam no impacto que produzem em seus recipientes;

- as variações do impacto de serviços públicos tendem a espelhar o status social, econômico e politico, isto é, serviços de melhor qualidade vão para os de status mais elevado;

- o administrador público está moralmente obrigado a se opor a essa tendência;

- a eqüidade na prestação de serviços, até onde possa ser calculada, deve ser um dos padrões pelos quais é julgada a "bondade" de um serviço público;

- as variações que se afastassem da eqüidade deveriam dirigir-se sempre no sentido de fornecer mais e melhores serviços àqueles em circunstâncias sociais, econômicas

e políticas inferiores; e

- o isolamento de administradores e órgãos públicos em relação à responsabilidade politica ou administrativa não contribui para a eqüidade.

Fazendo-se um contraste entre essa ética de administração proposta e as normas administrativas tradicionais descritas anteriormente, torna-se claro que elas estão em conflito no que se refere ao papel do administrador dentro de um órgão público. As diferenças mais notáveis são as de que a Nova Administração Pública: a) não dá ênfase à eficiência como um objetivo administrativo que transcende as consequeências sociais e psicológicas das atividades públicas; b) insiste para que os administradores públicos assumam atitudes politicas quando forem necessárias para garantir que se esteja alcançando a equuidade social através de seus programas e; c) insiste em que os administradores aceitem a impossibilidade de uma neutralidade de valores na execução de suas tarefas. Em resumo, 0 administrador é visto como um agente de mudanças, que trabalha essencialmente para garantir "a reduçăo do sofrimento econômico, social e psíquico e a melhoria das oportunidades de vida para aqueles dentro e fora da organização" 145 (pg. 32).

As reações dos administradores profissionais a essas propostas têm variado enormemente. $\mathrm{Em}$ um número recente, tipo simposio, de "Public Ma- 
nagement", 157 alguns administradores urbanos manifestaram seu firme apoio à orientação defendida pelo grupo da Nova Administração Pública. Outros fizeram fortes objeções às mudanças operacionais e de valores propostas, argumentando que a Nova AdministraÇão Pública: I-presume que os administradores públicos dispõem de mais poder do que realmente têm para efetuar modificações; II - é demasiado teórica em sua orientação; III - é demasiado idealista; IV - está pedindo que os administradores violem o "império da lei"; V-está propondo mudanças de valores que, se adotadas, levariam a graves conflitos entre diversos grupos de cidadãos; e VI-está propondo modificações nas práticas administrativas que poderiam levar a algo "parecido com anarquia".

Independentemente do aspecto de Validade, se um número substancial de administradores endossa esses argumentos contra a posição da Nova Administração Pública, será muito pequeno, a curto prazo, o potencial para implementação dos ingredientes da eqüidade sugeridos por Frederickson (e portanto, de um governo mais receptivo). De fato, sem uma mudança em direção a uma maior participação dos cidadãos, as previsões têm de ser pessimistas quanto à possibilidade de atrair grande número de administradores profissionais para a luta pela eqüidade. Para a maioria, o preço da aceitação parecerá alto demais. Isto $e ́$ as recompensas pessoais a serem derivadas da defesa de tal linha de ação provavelmente não equivalerão ao preço potencial previsto. Isso é so-
bretudo verdadeiro se os administra- dores relacionarem ameaças ao emprego com um engajamento na orientação da eqüidade, como ocorreu no simpósio da "Public Management" acima referido. Temos de ser realistas quanto ao fato de que hoje em dia poucas pessoas estão dispostas a seguir qualquer linha de ação que sintam que põe em risco seus empregos.

A despeito dessa estimativa pessimista, um número crescente de administradores públicos não teria dificuldade em reconhecer a necessidade de um governo mais receptivo e maior igualdade social. Há, dentro da profissão da administração pública, um desejo de servir ao interesse público, embora poucos administradores sejam "proativos" no sentido descrito por Harmon 18 e muitos não definam as necessidades da sociedade da mesma forma por que o faz o grupo da Nova Administração Pública. Com a combinação certa de preocupação pessoal, apoio e exigências vigorosos, os burocratas podem se tornar agentes de mudanças eficazes na busca de um governo que seja mais receptivo às necessidades de todos os cidadãos. 0 desafio reside em forçar essa reorientação em atitudes, valores e práticas. Atualmente a descentralização e a participação dos cidadãos oferecem a meIhor esperança de se criar o impulso político e administrativo necessário para se atingir os objetivos de eqüidade e de maior receptividade governamental, enquanto simultaneamente sejam atendidas as condições da sociedade $e$ as necessidades humanas mencionadas anteriormente neste trabalho. 
Implicações Administrativas

da Descentralização e da

Participação dos Cidadãos

Dadas a onipresença dos valores e perspectivas administrativas tradicionais e as reservas que os termos "participação dos cidadãos" tendem a evocar entre os administradores profissionais, parece agora essencial que se faça algum esforço para situar o conceito de descentralização-participação dos cidadãos em uma perspectiva. organizacional mais realista. Embora a exposição abaixo possa não alterar as prevenções administrativas tradicionais, ela indicará que as dificuldades e os desafios que uma maior participação dos cidadãos apresentará aos administradores públicos não significam, por definição, caos ou ineficiência.

Há várias formas possiveis de encarar a questão que poderiam ser adequadamente usadas para identificar as implicações administrativas da descentralização tal como aqui definida. Hallman, por exemplo, se concentrou em orçamento, pessoal, compras e diretrizes para execução de programas. 16 Frederickson sugeriu um conjunto muito mais amplo de categorias de avaliaçäo para essas análises. As categorias que propõe são: (a) processo distributivo, (b) processo integrativo, (c) processo de intercâmbio fronteiriço e (d) processo sócio-emocional. 14 Para nossa finalidade, três titulos amplos serão utilizados. Tomando emprestado a Frederickson, examinaremos os processos sócioemocional, integrativo e de intercâmbio fronteiriço. Exceto onde se indi- car diversamente, nos referiremos ao administrador regional, isto é, ao administrador que se encontra mais próximo da linha de fogo das operaçöes do dia a dia e por isso o que é mais afetado em suas atividades pelas conseqüências da maior participação dos cidadãos.

Deve-se observar que alguns dos projetados benefícios, tendências, dificuldades e desafios apresentados abaixo são meramente especulativos, enquanto que outros se baseiam em experiências específicas no nivel comunitário, nos setores de programas de ensino e de ação comunitária. Além disso, várias avaliações recentes trataram especificamente de diversos aspectos da receptividade governamental ou participação dos cidadãos sob uma perspectiva administrativa e a|udaram na formulação dessas projeçōes

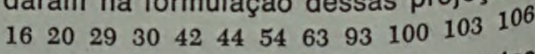
125153 . Encontram-se também várias implicações administrativas em avaliações de experiências específicas de descentralização no campo do ensino.

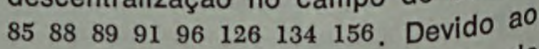
conflito que cercou o Programa de Ação Comunitária (PAC) e aos niveis de participação efetivamente alcançados em muitas cidades, algumas avaliações dos resultados de PACs também foram úteis. $77 \quad 100114116 \quad 117 \quad 119$ 129135 .

\section{Processo Sócio-emocional}

É preciso levar-se em consideraçăo os efeitos da participação dos cidadãos sobre os funcionários de um órgão público ao se pesar as conseqüências administrativas de tal parti- 
cipação. O processo sócio-emocional se refere à natureza das relações entre as pessoas - conflito, franqueza, confiança e cooperação - dentro da organização, com ênfase sobre 0 indivíduo e sobre o grupo. É nesse terreno que os administradores regionais provavelmente encontrarão alguns de seus mais complexos problemas. As projeções a seguir indicam dificuldades e problemas administrativos importantes associados com descentraliZação, participação dos cidadãos $\odot$ controle de distrito:

- podem levar a grandes conflitos entre profissionais e cidadãos a respeito de orientação e implementação de programas;

- podem levar a uma ênfase maior de sindicalização do funcionalismo para neutralizar esses conflitos, ou seja, maximizar a posição do servidor em qualquer situação de conflito;

- podem desencorajar a franqueza dentro da organização devido a que os servidores entendem a participação dos cidadãos como uma ameaça pessoal a eles próprios;

podem levar a divisionismo interno devido à formação de grupos de servidores que se colocam a favor ou em oposição da colaboração com os cidadãos em busca de um governo mais receptivo;

- podem levar a sentimentos de paranóia no meio de alguns servidores devido à sensaçăo de que tanto os cidadãos como os administradores estão "olhando por cima de seus ombros" (perspectiva profissional, ao contrário da pessoal referida acima);

- podem desencorajar algumas pessoas de procurar empregos públicos devido às pressões que os cidadãos poderiam exercer sobre elas;

- podem levar a um aumento do número de servidores que deixam o serviço público devido às pressões que a descentralização (como empregada aqui) traria consigo.

Por outro lado, é possível projetar os seguintes benefícios administrativos decorrentes da descentralização:

- pode minimizar a responsabilidade perante seus pares (no grupo profissional);

- pode encorajar mais pessoas com espírito de servir os cidadăos a procurar empregos no serviço público;

- pode tornar os empregos no serviço público mais atraentes e estimulantes para aqueles que atualmente os consideram como rotineiros, maçantes e sem vida;

- pode estimular os servidores a ter maior compreensão, dar mais valor e sentir mais dedicação em relação a um atendimento mais efetivo das necessidades humanas às quais o governo está res. 
pondendo ou devia estar tentando responder;

- pode abrir canais de comunicação entre os servidores devido à necessidade de esforço e dedicação comuns às tarefas tal como definidas.

A forte oposição dos professores à descentralização nas escolas em Nova York (vide Marilyn Gitell) indica a possibilidade de um desafio administrativo e uma reação de servidores a esforços de descentralização que permitam aos cidadãos "intrometer-se" no território proibido do profissional 135 $\begin{array}{llll}89 & 96 & 87 & 122\end{array}$. Em muitos casos os cidadãos exigirão mudanças nas operações e valores governamentais em vigor, algumas das quais são contrárias ao que os profissionais entendem ser de seu interesse. Como Roberts indicou em seu estudo do esforço de descentralização nas escolas em Nova York, "se está pondo em questão teorias de seleção de professores, qualificação, exercício do magistério, métodos e currículos - na verdade toda a ideologia profissional" 122 (pg. 117). Os profissionais na cidade julgaram essas posições ameaçadoras e, por via de conseqüência, totalmente inaceitável o conceito de descentralização. $O$ administrador pode ser apanhado no meio desse tipo de luta, principalmente quando há um conflito visível entre as necessidades ou desejos dos cidadãos e as exigências dos servidores relativas à manutenção ou melhoria de suas posições dentro do órgão ou repartição. o equilibrismo pode ser difícil, porém é uma tarefa necessária para que se R. Serv. públ., Brasilia, 108 (3) set./dez. 1973 possa aumentar a qualidade e a eqüidade dos serviços públicos enquanto também são atendidas as necessidades sócio-emocionais dos servidores.

Como alguns servidores públicos considerarão a participação dos cidadãos uma ameaça tanto pessoal quanto profissional, pode-se também es. perar que eles aceitarão a idéia de que a única forma certa de proteger seus direitos é tornar-se membros de um sindicato. A expectativa clara será a de que através do número de membros, seus direitos, prerrogativas $e$ poderes serão mantidos. As implicações administrativas da sindicalização do funcionalismo têm sido alvo de considerável preocupação na profissão e nas obras especializadas, não precisando ser examinadas aqui, 164 165. É importante compreender-se que essa sindicalização ampliada resultará em maiores esforços para reforçar as exigências e necessidades dos servidores, não dos cidadãos. $\mathrm{CO}^{-}$ mo resultado, os dirigentes precisam adquirir mais consciência da necessidade de uma orientação de "interesse público" e estar dispostos a lutar por ela na mesa de negociações. O maior desāfio administrativo decorrente da descentralização-participação dos cidadãos no âmbito do processo sócioemocional parece assim residir no equilibrio entre as necessidades dos cidadãos e as exigências dos servidores.

\section{Processo Integrativo}

$O$ processo integrativo se refere aos meios pelos quais se faz a coordenação do trabalho das pessoas em uma 
organização administrada oficialmente, ou seja, a administração das operações internas de um órgão governamental. A maioria dos opositores da administração participativa concentrou sua atenção nessa área, basicamente em virtude de seus fortes desejos por operações "eficientes" de administração interna. Embora algumas das dificuldades mencionadas abaixo possam de fato reduzir a eficiência interna, a questão crucial a ser considerada é se a perda em eficiência é compensada pelos beneficios obtidos tanto em termos de operações internas como de produção do serviço. Pode-se efetuar projeções dos seguintes tipos de principais dificuldades e problemas que resultarão da descentralização:

- pode agir contra a eficiência tal como tradicionalmente definida, isto é, pode retardar o processo de tomada de decisão e complicar o processo de implementação;

- pode resultar na descentralização de alguma parcela da tomada de decisão, enquanto deixa que se mantenha poder no topo, limitando assim as opções abertas ao administrador regional na execução de seus deveres;

- poderia levar a conflito entre os órgãos central e setoriais a respeito de padrões administrativos e procedimentos operacionais, especialmente à medidà em que os administradores chegados ao povo comecem a desenvolver diretrizes que atenderăo suas ne- cessidades de maneira mais eficaz;

- pode levar ao caos e à confusão administrativos a propósito de direção e objetivos governamentais;

- pode criar um estado de confusão em relação à cadeia de comando dentro dos órgãos públicos;

- pode ser difícil convencer os administradores do escalão superior a adotarem uma orientação de se abster de interferir nas operações governamentais nos niveis operacionais ou distritais;

- requer que o administrador regional sirva a dois ou três senhores - órgão central, os cidadãos e talvez um especialista do corpo central.

A descentralização poderia, entretanto, resultar nos seguintes beneficios administrativos:

- pode levar ao desenvolvimento de direção e propósito comuns, por exemplo uma orientação em direção a algo tão genérico como a eqüidade ou tão especifico como um programa governamental determinado;

- pode levar a novos métodos de avaliação de serviços que incorporem de forma mais completa tanto os objetivos da administração como os desejos e entendimentos da clientela; 
- pode habilitar a administração a reagir de forma mais efetiva aos desafios próprios de uma subdivisão governamental (distrito);

- pode auxiliar órgãos a desenvolver programas mais eficazes e oferecer serviços de maneira mais eficiente devido à oportunidade de uma reação imediata;

- pode levar a algumas economias de custos porque os cidadãos podem auxiliar indicando programas desnecessários, projetos com desperdicios e opções mais factiveis dadas características especificas da comunidade.

Os problemas delineados acima indicam vários desafios administrativos no âmbito do processo integrativo. Um dos mais importantes seria servir vários senhores simultaneamente. administrador regional será colocado numa situação em que tem de reagir tanto aos desejos (exigências) dos cidadãos como da administração central. Na maioria das situações governamentais descentralizadas é preciso contar-se com que os administradores regionais não terão seus sentimentos básicos de lealdade dirigidos para 0 distrito. 124 Como é a administração central que toma as decisões em relação a promoções e salários, é de se esperar que atenção especial será sempre prestada aos desejos da administração de nivel superior. Ao mesmo tempo, entretanto, a descentralização indicará aos cidadãos que eles terăo maior voz ativa no processo administrativo. Se os cidadãos perceberem que o administrador regional é um fantoche dos administradores de nivel superior, que ele não pode atuar sem a aprovação do nivel superior em muitas questões de diretrizes, ou que ele não está imbuido de um senso de responsabilidade para com a comunidade, sua credibilidade e utilidade no distrito terão curta duração. Assim, 0 desafio à administração regional reside em equilibrar a fidelidacie à administração central com um senso de responsabilidade para com o distrito. A tarefa de contentar a ambos grupos será em muitos casos bastante difícil.

É também importante o fato de que os servidores terão exigências a formular ao administrador. Ele tem assim de ser capaz de lidar com dois senhores externos que lhe estarão constantemente fazendo exigências, enquanto internamente os servidores também terão expectativas e necessidades que têm de ser atendidas. Esse fator adicional tornaria ainda mais dificil para o administrador regional ser fiel aos cidadãos, especialmente à luz das prevenções e orientações dos servidores examinadas na seção anterior.

Um outro desafio consiste na necessidade de um administrador que $\mathrm{se}^{-}$ Ja capaz de fornecer direção para as atividades burocráticas no nivel distrital. A despeito das numerosas e conflitantes exigências que the são feitas. bem como dos períodos que poderiam retardar a tomada de decisões, o administrador deve demonstrar capacidade de liderança, ao mesmo tempo em que mantém as operações em sua área desenrolando-se suavemente. Ele deve ser capaz de livrar do caos ocasional planos viáveis que serão acei- 
táveis para cidadãos, servidores e suPeriores administrativos. Ele deve ser capaz de trabalhar com os cidadãos num esforço para ficar dentro das limitações de tempo que se impõem a todas as organizações. Essa necessidade de capacidade de liderança administrativa e de organização é particularmente crucial e não deve ser subestimada caso se deseje que as subdivisões governamentais demonstrem esforços para lograr operações razoavelmente eficientes. Como a eficiên$\mathrm{Cla}$ seria necessariamente definida em termos um tanto diferentes dos atuais, essa realidade pode de fato ser interpretada para significar que os administradores devem ser capazes de mostrar que, dados os atrasos que seriam de esperar com um aumento do número de pessoas que têm de Participar dos processos de tomada de decisões e de execução, os métodos operacionais mais eficientes estão sendo empregados.

De possivel importância administrativa é o grau em que o administrador regional consegue convencer a administração de que lhe deveria ser atribuida uma alta dose de flexibilidade na tomada de decisões. Quando a administração central não dá ao administrador regional uma grande margem de latitude para levar a cabo seu Programa, seu trabalho será tanto mais difícil. Embora em alguns casos Possa ser particularmente duro conVencer a central a manter uma política razoável de não-intervenção, os administradores no nivel distrital devem Procurar obter alguma garantia de am$\mathrm{Pla}$ latitude para atender aos problequotidianos que têm de enfrentar.
Se essa liberdade não the for concedida, o administrador regional provavelmente verificará ser impossivel responder aos tipos de desafios suscitados em um ambiente de crise e, o que é mais importante, Ihe será difícil tomar as decisões rápidas que os administradores devem ser capazes de adotar à medida em que surgem os problemas.

Um outro desafio importante para os administradores públicos em termos do processo integrativo consistirá em equilibrar as formas tradicionais de funções administrativas, tais como pessoal e orçamento, com desafios oferecidos pelo distrito e que conflitam com aqueles procedimentos. É de se esperar que os esforços para se continuar agindo "como de hábito" nos órgãos públicos seja objeto de contestação cada vez maior à medida em que os cidadãos participem mais das atividades administrativas. $\mathrm{Na}$ área de pessoal, por exemplo, quase certamente serão feitas exigências para que os critérios tradicionais do serviço público em relação ao emprego público sejam reavaliados e possivelmente alterados a fim de aumentar as oportunidades de trabalho para segmentos maiores da população, em especial para os residentes do distrito. 2042 Além disso, serão provavelmente apresentados argumentos em favor de padrões de "merecimento" revistos, que não produzam o efeito de perpetuar a discriminação econômica, racial e de sexo no serviço público. Os residentes na comunidade, em especial, sem dúvida atribuirão relevância maior à contratação pelas administrações locais de um número substan- 
cialmente maior de burocratas de nivel térreo - professores, policiais no seio das comunidades a que servem. 103 As entidades governamentais e seus administradores precisam estar preparados para responder a essas exigências de requisitos de pessoal modificados e de diretrizes que possam servir para maximizar a receptividade governamental e a "capacidade de aquilatar necessidades" como resultado do maior emprego de residentes da comunidade. Um desafio igual será a oportunidade de trabalhar intimamente com pessoas que estão altamente cônscias dos problemas da comunidade e estão firmemente empenhadas em atender essas necessidades numa base prioritária.

Ao longo de linhas análogas, a descentralização também oferecerá maiores oportunidades para que os cidadãos e as juntas distritais, em especial, examinem em detalhe o processo orçamentário governamental e apresentem a respeito contribuições mais vigorosas. Seria de esperar que essa oportunidade para uma participação ampliada dos cidadãos levasse, em última análise, a exigências de novas medidas relativas a produtividade e/ou eficácia de programação. Em muitos casos os administradores serão intimados a justificar gastos em termos de benefícios recebidos pelos residentes do distrito e, talvez, os métodos empregados na prestação de serviços. Assim, na medida em que responsabilidades por decisões orçamentárias sejam descentralizadas para o administrador regional, ele será colocado na posição potencialmente controvertida e talvez fraca de questionar pes- soalmente diretrizes e programas na busca de um governo mais receptivo. no nivel distrital.

Em suma, o êxito no desempenho da função integrativa num esquema descentralizado provavelmente será produto de: (a) capacidade de liderança do administrador regional; (b) grau de autonomia atribuido ao administrador regional para fixar diretrizes e tomar decisões operativas; (c) grau de realce atribuido à noção tradicional de eficiência pela administração central ao avaliar as operações regionais; (d) capacidade da administração de convencer os cidadãos de que os dirigentes e funcionários regionais têm um sentido de responsabilidade para com eles tanto quanto para com a administração central; $e$ (e) capacidade do administrador de resolver os conflitos entre práticas administrativas "tradicionais" e exigências dos residentes do distrito de modificações nessas atividades e em diretrizes com elas relacionadas.

\section{Processo de Intercâmbio Fronteiriço}

O processo de intercâmbio fronteiriço se refere ao relacionamento geral entre a organização administrada publicamente e seus grupos de referência e clientes, inclusive assembléias legislativas, autoridades eleitas, organizações de pessoal auxiliar, cidadãos em caráter individual, grupos de pressão organizados e outros níveis de $\mathrm{go}^{-}$ verno. 14 Dentro do contexto deste ensaio, uma avaliação do processo de intercâmbio fronteiriço exigiria uma concentração especial em relações administração-clientela, atividades de 
funcionários eleitos pela administração - efeitos sociais genéricos do movimento de descentralização. Os princiPais problemas e dificuldades administrativos relacionados com intercâmbio fronteiriço num esquema descentralizado incluem:

- poderá obrigar os administradores a assumir atitudes políticas que conflitam com as de autoridades eleitas devido às pressões dos cidadãos;

- poderá levar a maiores lutas internas entre as "confrarias" e grupos locais em competição a propósito de rumos de diretrizes;

- poderá resultar em que se atribua poder a alguns poucos cidadãos que poderão tiranizar a maioria;

- sujeitará o administrador regional a uma dose aumentada de pressão política por parte dos residentes do distrito;

- criará um ambiente de trabalho mais carregado de controvérsias;

- poderá criar situações de emprego vulneráveis devido às posições controvertidas que os administradores podem ser obrigados a assumir;

- criará muitas situações administrativas imprevisíveis, para cujo enfrentamento os administradores não possuem preparação acadêmica, antecedentes sociais ou expariência;
- poderá forçar o administrador a se envolver em controvérsias da comunidade que mais tarde o prejudicarão independentemente da posição que houver adotado;

- poderá levar a conflitos crescentes entre autoridades eleitas e administradores a respeito de decisões sobre diretrizes e formas de implementação.

A descentralização poderia, contudo, induzir aos seguintes beneficios administrativos no processo de intercâmbio fronteiriço:

- estabelecimento de maior proximidade física com as pessoas que são servidas;

- poderá reforçar a posição do administrador perante seus superiores e autoridades eleitas devido ao claro apoio da comunidade;

- poderá dar aos administradores uma oportunidade de se tornarem importantes agentes de mudanças sociais;

- poderá levar a relações de trabalho mais intimas, bem como a maior compreensão mútua e sentimento de respeito, entre administradores e cidadãos;

- criaçäo de oportunidades para que administradores e servidores vejam com maior clareza e "sintam" o impacto de seus esforços para melhorar o padrão de vida dos cidadãos em seus distritos; 
- poderá levar a uma inversão da atitude dos cidadãos a respeito da falta de receptividade governamental para suas necessidades;

- poderá conduzir à redução de muitos sentimentos de hostilidade e frustração atualmente encontrados em especial no meio de grupos de baixo nivel de renda;

- poderá apagar muitas das concepções erradas que os servidores públicos têm do cidadão "médio". e, em especial, dos que compõem grupos sócio-econômicos inferiores;

- poderá contribuir para desfazer as atitudes de alguns funcionários públicos de se considerarem membros de uma elite.

O primeiro desafio importante administrativo que surge na área do intercâmbio fronteiriço consiste em fazer funcionar um órgão público dentro de um meio ambiguo e potencialmente frustrante. $\mathrm{O}$ administrador tem, em um esquema descentralizado, imensas oportunidades para trabalhar intimamente com os cidadãos e ver os resultados de seus esforços mais criativos, bem como de seus fracassos. Suas relações com o conjunto dos cidadãos pode ajudá-lo quando buscar apoio na administração central ou junto a autoridades eleitas para seus programas distritais. Ao mesmo tempo, é claro que os cidadãos poderiam objetar a suas diretrizes e se tornar antagonistas que se oporiam firmemente a ele em torno de questões grandes e pequenas. Se o administrador não possuir um enorme sentimento por sua comunidade, se ele não compreender os motivos dos cidadãos que o procuram (com sua agenda oculta), se ele não tiver uma noção de perspectiva a respeito dos conflitos de poder dentro do distrito, e se ele não possuir um sentido de oportunidade para maximizar seus esforços e minimizar a oposição a eles, então a descentralização poderá se revelar muito frustrante. O desafio está em apreender a dinâmica do distrito de maneira que ele (o administrador) possa trabalhar eficientemente com os cidadãos a fim de satisfazer suas necessidades de forma mais eficaz.

Para alguns administradores, tornar-se mais politicos num esquema descentralizado constituirá um desafio maior. Os administradores têm tradicionalmente evitado ficar em evidência ao desempenhar suas funções e se têm mostrado ciosos de evitar conflitos sempre que possivel. A participação dos cidadãos tornará isso mais difícil. Será mais complicado passar a bola adiante para evitar tomar decisőes dificeis. Essa proximidade com os cidadãos trará consigo responsabilidades de diariamente tomar decisőes que poderão levar a controvérsias. Ela forçará o administrador a, ocasionalmente, assumir posições políticas que de outra maneira não adotaria, precipuamente por motivos de subrevivência. $O$ desafio residirá em aceitar 0 inevitável e se tornar um político eficiente, que será, em certas ocasióos, obrigado a tomar firmes atitudes politicas no interesse público. $O$ direito 
das autoridades eleitas de traçar diretrizes não seria posto em dúvida, porém o administrador pode ser obrigado a trabalhar com mais empenho para convencer essas autoridades (direta ou indiretamente) da importância dos programas que advoga.

\section{Habilidades Administrativas Essenciais}

Os problemas e desafios mencionados acima indicam a necessidade de Várias habilidades administrativas que Parecem essenciais para uma administração eficiente em uma operação governamental descentralizada que incite a participação dos cidadãos. As mais importantes dessas habilidades são:

1. Capacidade de atuar com eficiência em situações de conflito. O administrador deve possuir habilidade de barganha tal que possa lidar com os cidadãos e com os servidores quando surgem conflitos e deve possuir habilidade de negociação que the dê condições de trabalhar com autoridades eleitas e pessoal do órgão central Para dar solução aos conflitos quando surgirem ou forem pressentidos.

2. O administrador deve estar muito familiarizado com a dinâmica do grupo. Isso significa capacidade de entender como e por que os grupos são formados e desaparecem, o que estăo procurando alcançar e qual a melhor forma para se trabalhar com oles.

3. O administrador deve ser ca$\mathrm{Paz}$ de entender os sentimentos, exigências, frustraçöes e esperanças dos cidadãos com os quais trabalha. Isso frequentemente pode significar estabelecer relacionamento com pessoas com caracteristicas econômicas e raciais, bem como com critérios de valor, totalmente diferentes.

4. O administrador deve ser capaz de trabalhar dentro de um esquema em que seja responsável perante vários chefes e, o que é mais importante, no qual os desejos desses chefes podem conflitar entre si.

5. O administrador deve ser capaz de atuar em situações de trabaIho muito fracas e altamente incertas, nas quais seja difícil definir soluções perfeitamente delineadas e as condições ambientais estejam se modificando constantemente.

6. O administrador deve estar disposto a aceitar a inevitabilidade e talvez a conveniência de uma mobilidade maior dentro da profissão. Tal como os administradores urbanos tendem a se deslocar cada três a cinco anos, assim também deveriam fazer os administradores regionais quando mudem as condições em suas comunidades e/ou mudem seus interesses ou necessidades. Algumas das tensões que acompanham esse tipo de emprego também podem exigir tal mobilidade.

7. O administrador deve se tornar mais astuto politicamente. Ele tem de entender que de fato toma decisões políticas e, de uma certa forma, partilha a função de formulação de diretrizes com as autoridades eleitas. Sua proximidade do conjunto de cidadãos 
pode, na realidade, colocá-lo muito mais perto do povo do que muitos de seus representantes eleitos. Isso terminará por obrigar os administradores a se tornarem mais políticos do que muitos provavelmente prefeririam ser.

8. O administrador precisa ter uma enorme capacidade de comunicação, que o habilite a estabelecer relacionamentos, nos dois sentidos dos canais burocráticos, de seus sentimentos com cidadãos e com autoridades eleitas. Ele deve, ao mesmo tempo, ser um bom "ouvinte", capaz de extrair da massa de dados que recebe as informações essenciais para o eficiente desempenho de suas tarefas administrativas.

9. O administrador deve ser capaz de se livrar da imagem de pessoa distanciada e de elite que muitos cidadãos atribuem aos administradores profissionais.

Embora a eficiência nessas áreas não garanta êxito na atuação dentro de um esquema administrativo de participação, ela representa um acréscimo crucial tanto para a experiência de trabalho como para o entendimento fundamental de conceitos básicos de administração. Deve-se ressaltar, entretanto, que a habilidade, tal como a tecnologia, pode ser usada para fins bons ou maus. A pertinência dessas habilidades depende, em última análise, da filosofia do administrador e de seu correspondente sentido de ética. A questão crucial de que nós na profissão nos devemos ocupar é se os programas da administração pública estão tentando assistir tanto o estu- dante quanto os profissionais no desenvolvimento dessas habilidades administrativas junto com um quadro de referência filosófico montado em torno dos princípios democráticos fundamentais.

\section{Implicações para as Escolas de Administração Pública}

A participação dos cidadãos em assuntos públicos tem uma significação especial para as escolas de administração pública. As habilidades administrativas referidas acima como sendo essenciais para uma administração eficiente dentro de um sistema administrativo descentralizado também acarretam implicações para o ensino de administração pública. Seguese um debate sobre a ênfase que pode ser considerada para a inclusáo nos currículos de administração de cada uma das áreas de diretrizes examinadas neste número especial ( $\mathrm{po}^{-}$ lícia, ensino, assistência social, saúde), bem como para os programas de administração pública em geral. Essas áreas de ênfase, por sua vez, indicam técnicas que poderiam ajudar os alunos a desenvolver o complemento supracitado de habilidades administrativas.

Conquanto seja dificil fazer qualquer relação completa dos muitos fenômenos que deveriam ser enfatiza. dos em nossos programas profissionais, os que examinaremos abaixo parecem ter uma significação especial dentro do quadro de descentralizaçăo aqui descrito: Propõe-se que os programas de administração pública emprestem maior ênfase à interação hu- 
Mana, experiência, capacidade e processos, e confiem menos em regras e procedimentos autoritários. Isso implica especificamente atribuir maior ênlase ao desenvolvimento da habilidade de comunicação de profissionais e não-profissionais, inclusive informação sobre como estabelecer e manter, de forma eficaz, a comunicação com os cidadãos. Para consegui-lo será importante utilizar-se exercícios simulados e estimulantes. Será igualmente importante o oferecimento de oportunidades Para a interação de pequenos grupos em projetos de pesquisa, sessões de formulação de diretrizes e exercícios de solução de problemas.

Os administradores provavelmente terăo de começar a lidar de forma mais explicita com questões de valor Principais e temas claramente relacionados com necessidades humanas e Provisão de serviços públicos. Serão cada vez mais comuns as experiências em condições de laboratório e de vida real que requererão uma avaliação não de como e a quem os serviços são prestados, mas de como as pessoas sentem a respeito desses serviCos. Os alunos precisam fazer mais do que ler sobre casos e escrever monografias descrevendo implicaçöes de valor para os protagonistas nesses casos, não importa o quanto isso tenha sido útil em sua época. E é imPortante tratar explicitamente da questão da descentralização-participação dos cidadãos no âmbito de seminários O examinar implicações, desafios, inovações e experiências na prática real.

Os alunos do ensino de administrafão precisam dedicar mais atenção à análise de questões importantes e con- trovertidas de diretriz pública. É essencial dar aos alunos uma base em processo de análise e equipá-los para lidar com a controvérsia antes que cheguem à linha de tiro. Isso sugere atribuir maior ênfase à análise em profundidade de diretrizes, a qual requer que os alunos devotem atenção à formulação de temas, identificação de opções para diretrizes, implicações e possíveis conseqüências das alternativas identificadas.

É importante proporcionar aos alunos oportunidades para trabalhar em situações de conflito. Para isso são úteis diversas formas de treinamento sócio-emocional (treinamento de sensibilidade, desenvolvimento de organização, etc.) É também útil proporcionar incumbências (talvez na forma de escritório utilizada por planejadores e arquitetos) que permitam aos alunos levar a cabo projetos práticos importantes, que exijam interação com cidadãos, burocratas e autoridades eleitas, e que incluam uma apresentação de conclusões perante uma banca de críticos.

O futuro ensino de administração pública provavelmente atribuirá maior ênfase à percepção pelo aluno das realidades sociais, psicológicas e econômicas da vida urbana e à natureza Interrelacionada desses fatores. Estes podem então ser correlacionados com as áreas profissionais específicas em que o aluno deverá trabalhar. As experiências práticas são essenciais para ampliar a base dos alunos na área dos problemas sociais e necessidades humanas no âmbito urbano. 
Provavelmente será necessário dispensar maior atenção às relações servidor-administração a fim de auxiliar os novos administradores a atender de forma mais eficaz às necessidades sócio-emocionais dos servidores públicos.

Em resumo, o ensino de administração pública precisa se tornar mais orientado para ação, valor e diretriz, a fim de que possa preparar adequadamente os alunos para atuar em ambientes de participação. Não se deve minimizar a importância da familiaridade com conceitos administrativos fundamentais, mas esses fundamentos não mais podem constituir a única ênfase. As escolas de administração pública comumente não estão bem equipadas para ensinar valores, porém tais escolas não podem mais evitar discutir valores e exigir que seus alunos avaliem suas próprias percepções e orientações em relação a temas e problemas públicos principais. Sugere-se também que se dê maior atenção à questão da receptividade governamental e da maior eqüidade social. Analogamente, mais atenção deve ser dada às tendências a um espirito de elite na profissão do serviço público.

Tais modificações no ensino de administração pública não assegurarão que o governo acabará por se tornar mais receptivo às necessidades dos cidadãos. Nem a descentralização garante receptividade. Entretanto, quando combinadas, elas pintam um quadro de esperança numa época de desespero. Precisamos começar a educar os administradores públicos crian-

R. Serv, públ., Brasilia, 108 (3) set./dez. 1973 do neles a noção de que uma maior descentralização - participação dos cidzdãos é não só desejável como inevitável. Independentemente do que ocorra depois, provavelmente teremos produzido administradores e servidores públicos mais capazes, dedicados, receptivos e humanos. Em última análise, talvez este seja o real sentido da participação dos cidadãos.

\section{REFERENCIAS}

Perspectivas para a Sociedade e a Burocracia norte-americanas

1. Edward C. Banfield, Political Influence (New York: Free Press, 1961).

2. Raymond A. Bauer, et al., second Order Consequences: A Methodological Essay on the Impact of Technology (Cambridge, Mass.: The M.I.T. Press, 1969).

3. Warren Bennis and Philip E. Slater, The Temporary Society (New York: Harper and Row, 1968).

4. Kenneth Blanchard and Paul Hersey, Management of Organizational Behavior $(E 9)$. nagement of Organizational Behavil, 1969).
glewood Cliffs, N.J.: Prentice-Hall,

5. Frances R. Cousens, Public Civil Rights and Fair Employment: Promise vs. Perfor mance (New York: Frederick A. Praeger 1969).

6. Michael Crozier, The Bureaucratic PhenoMichael Crozier, The Bureaucratic Chicago $^{\circ}$
menon (Chicago: University of Chs 1964).

7. Ishwar Dayal, "Some Dilemmas in Newer" Concepts of Administration," Californial Management Review, Vol. XIII, N. ${ }^{0}$ (Fal 1970), pp. 51-58.

8. Mathew P. Dumont, "The Changing Face of Professionalism," Social Policy June 1970), pp. 26-31.

9. Jacques Ellul, The Technological Society (New York: Vintage Books, 1964).

10. Victor C. Ferkiss, Technological Man: The Myth and the Reality (New York: Georg Braziller, 1969). 11. James Fesler, Area and Administration
(University, Ala: University of Alabama Press, 1949). 
12. Thomas A. Flinn and Carl Stokes, Local Government and Politics: Analyzing Decision-Making Systems (Glenview, III.: Scott, Foresman and Co., 1970).

13. H. George Frederickson, "Recovery of Structure in Public Administration," Pamphlet N.O 5 (Washington, D. C.: Center for Governmental Studies, 1970).

14.

Public Administration," "Toward a New (ed), Toward a New Public Administration (Scranton: Chandler, 1971), pp. 309-331.

15. John K. Galbraith, The New Industrial State (Boston: Houghton-Mifflin Co., 1967).

16. Howard W. Hallman, "Administrative Decentralization and Citizen Control," Pamphlet N.0 7 (Washington, D. C.: Center for Governmental Studies, 1971).

17. David R. Hampton, Organizational Behavior and the Practice of Management (Glenview, III.: Scott, Foresman and Co., 1968).

18. Michael Mont Harmon, "Administrative Policy Formulation and the Public Interest," Public Administration Review, Vol. XXIX, N. ${ }^{\circ} 5$ (September/October 1969), pp. $483-491$.

19. Michael Harrington, The Accidental Century (Baltimore: Penguin Books, Inc. 1967).

20. Mark A. Haskell, The New Careers Concept: Potential for Public Employment of the Poor (New York: Praeger, 1969).

21. Adam W. Herbert, Municipal Charter Reform: The Los Angeles Experience From a Minority Group Perspective, unpublished Ph.D. dissertation (Pittsburgh: University of Pittsburgh, 1971).

22. Everette C. Hughes, Men and Their Work (Glencoe, III.: Free Press, 1958).

23. Floyd H. Hyde, "Government-Master or Servant of the People?" Western City Magazine, Vol. XLVII, N. ${ }^{\circ} 9$ (September 1971), pp. 19-24.

24. Thomas L. Jacobs, "Positive Action for Improved City Management," Nation's Cliles, Vol. 8, N.0 11 (November 1970), pp. 14-17.

25. Mark E. Keane, "City Hall's Management Challenger," Nation's Cities, Vol. 8, N.० 6 (June 1970), pp. 24-30.

26.

Wilma R. Krauss, "Toward a Theory of Political Participation of Public Bureaucrats," Administrative Science Quarterly, Vol. 16, N.0 2 (June 1971), pp. 180-191.
27. Todd R. LaPorte, "The Context of Technology Assessment: A Changing Perspective for Public Organization," Public Administration Review, Vol. XXXI, N. ${ }^{\circ} 1$ (January/February 1971), pp. 63-74.

28. James A. McCann, "Is City Hall Getting the Job Done?" Nation's Cities, Vol. 8, N. 11 (November 1970), pp. 26-28.

29. Marvin Meade, '"Participative' Administration-Emerging Reality or Wishful Thinking?" in Dwight Waldo (ed.), Public Administration in a Time of Turbulence (Scranton: Chandler, 1971), pp. 169-187.

30. Raymond E.. Miles and J. B. Ritchie, "Participative Management: Quality or Quantity," California Management Review, Vol. XIII, N.॰ 4 (Summer 1971), pp. 48-56.

31. Frederick C. Mosher, "The Public Service in the Temporary Society," Public Administration Review, Vol. XXXI, N. ${ }^{\circ} 1$ (January/February 1971), pp. 47-62.

32. Frederick P. Mosher, Democracy in the Public Service (New York: Oxford University Press, 1968).

33. Felix A. Nigro, "The Implications for Public Administration," Public Administration Review, Vol. XXVIII, N. 2 (March/April 1968), pp. 137-147.

34. Marvin E. Olsen, "Social and Political Participation of Blacks," American Sociological Review, Vol. 35, N.० 4 (August 1970), pp. 682-696.

35. Michael Parenti, "Power and Pluralism: A View From the Bottom," Journal of Politics, Vol. 32, N.० 3 (August 1970), pp. 501-530.

36. John M. Pfiffner and Frank P. Sherwood, Administrative Organization (Englewood Cliffs, N. J.: Prentice-Hall, 1960).

37. Richard M. Pious, "Policy and Public Administration: The Legal Services Program in the War on Poverty," Politics and Society, Vol. 1, N.॰ 3 (May 1971), pp. 365-392.

38. H. G. Poe, "What's Ahead for Local Government Structure," Public Management, Vol. 53, N.0 7 (July 1971), Pp. 28-30.

39. Rollin B. Posey, "The New Militancy of Public Employees," Public Administration Review, Vol. XXVIII, N. ${ }^{\circ} 2$ (March/April 1968), pp. 111-117.

40. Emmette S. Redford, Democracy in the Administrative State (New York: Oxford University Press, 1969).

41. Charles A. Reich, The Greening of America (New York: Random House, 1970). 
42. Ned A. Rosen and Gustave Serino, "The Impact of Employee Selection Practices in Three Local Governments on Potential Black Personnel," Public Personnel Review, Vol. XXXII, N.० 3 (July 1971), pp. 164-168.

43. David H. Rosenbloom, "Citizenship Rights an Civil Service: Old Issue in New Phrase," Public Personnel Review, Vol. XXXI, N. 3 (July 1, 1970), pp. 180-184.

44.

tions of the "Some Political Implicathe Drift Toward a Liberation of Federal Employees," Public Administration Review, Vol. XXXI, N.० 4 (July/August 1971), pp. $420-426$.

45. Theodore Roszak, The Making of a Counterculture (Garden City, N. Y.: Anchor Books, 1969).

46. William G. Scott, "Organization Government: The Prospects for a Truly Participative System," Public Administration Review, Vol. XXIX, N.O 1 (January/February 1969), pp. 43-53.

47. Peter Self, “Elected Representatives and Management in Local Government: An Alternative Analysis," Public Administration, Vol. 49 (Autumn 1971), pp. 269-277.

48. Peter Selznick, TVA and the Grass Roots (Berkeley: University of California Press, 1949).

49. Gideon Stoberg. Richard A. Brymer, and Buford Farris, "Bureaucracy and the Lower Class." Sociology and Social Research (April 1966), pp. 325-337.

50. B. C. Smith and J. Stanyer, "Administrative Developments in 1969: A Survey," Public Administration, Vol. 48 (Autumn 1970).

51. William C. Thomas and Herman E. Hilleboe, "Administrative Centralization versus Decentralization and the Roles of Generalists and Specialists," American Journal of Public Health, Vol. 58 (September 1968), pp. 1620-1632.

52. Alvin Toffler, Future Shock (New York: Random House, 1970).

53. Dwight Waldo, "Development of the Theory of Democratic Administration." American Political Science Review, Vol. XLVI (March 1952).

54. Dwight Waldo (ed.), Public Administration In a Time of Turbulence (Scranton: Chandler, 1971).

55. Robert E. Walsh, Sorry... No Government Today: Unlons vs. Clity Hall (Boston: Beacon Press, 1969).

R. Serv. públ., Brasília, 108

(3) set./dez. 1973
56. James A. Wechsler, "Civil War in New York," Progressive, Vol. 33 (January 1969), pp. 20-30.

57. Orion F. White, Jr., "Organization and Administration for New Technological and Social Imperatives," in Dwight Waldo (ed.), Public Administration in a Time of Turbulence (Scranton: Chandler, 1971), pp. 151-168.

58. "The Dialectical Organization: An Alternative to Bureaucracy," Public Administration Review, Vol. $X X \mid X$, N. ${ }^{0} 1$ (January/February 1969), pp. 32-42.

59. Herbert G. Wilcox, "Hierarchy, Human Nature, and the Participative Panacea," Public Administration Review, Vol. $X X \mid X$ N. ${ }^{\circ} 1$ (January/February 1969), pp. 53-66.

60. James Q. Wilson and Edward C. Banfield, "Public Regardingness as a Value Premise in Voting Behavior", American Political Science Review, Vol. LVIII, N.O 4 (December 1964), pp. 876-887.

61. William Winter, The Urban Policy (NeW York: Dodd, Mead \& Co., 1969).

62. Raymond E. Wolfinger and John Osgood Field, "Political Ethos and the Structure of City Government," American Political Science Review, Vol. LX, N. 2 (June 1966), pp. 306-326.

\section{Leituras sobre Democracia e Administraçăo Participativas}

63. Robert A. Aleshire, "Organizing for Neighborhood Management: Drawing on tha Federal Experience," Public Management, Vol. 53, N. ${ }^{\circ} 1$ (January 1971), pp. 7-9.

64. Alan Altshuler, Community Control (New York: Pegasus, 1970).

65. Chris Argyris, Understanding Organizational Behavior (Homewood, III.: The Dorsey Press, 1960).

66. Sherry R. Arnstein, "A Ladder of Participation," Journal of the American Institute of Planners, Vol. 35 (July 1969), pp. 216. 224.

67. Stanley Aronowitz, "The Dialetics of Com" munity Control," Social Policy (May/June 1970), pp. 47-51.

68. Betram Belk, "Community Control: A Distraction Not An Answer," Soclal Work. Vol. 14 (October 1969), pp. 14-20.

69. Charles M. Bonjean and Michael D. Grlmes, "Bureaucracy and Alienation: A Dimensional Approach," Social Forces, Vol. 43. N.0 3 (March 1970), pp. 365-372. 
70. George A. Brager and Valerie Jorris, "Bargaining: A Method of Community Charge, " Social Work, Vol. 14 (October 1969), pp. 73-83.

71. Stanley J. Brody, "Maximum Participation of the Poor: Another Holy Grail?" Social Work, Vol. 15, N. ${ }^{\circ} 1$ (January 1970).

72. Barlow Burke Jr., "The Threat to Citizen Participation in "Model Cities," Cornell Law Review, Vol. 56, N. ${ }^{\circ} 5$ (May 1971), pp. 751-779.

73.

"Urban Public Policy Participation Network," Urban and Social Change Review, Vol. 3, N.o 2 (Spring 1970), pp. 15-19.

74. Edmund M. Burke, "Citizen Participation Strategies," Journal of the American Institute of Planners, Vol. 34 (September 1968), pp. 287-294.

75. O.A. Davis and K.O. Kortanck, "Centralizalion and Decentralization: The Political Economy of Public School Systems, American Economic Review, Vol. LXI, N.0 2 (May 1971), pp. 456-462.

76. John C. Donovan, The Politics of Poverty (New York: Pegasus, 1967).

77. Sumati N. Dubey, "Community Action Programs and Citizen Participation: Issues and Confusions," Social Work, Vol. 15. N.0 1 (January 1970), pp. 76-84.

78. Peter K. Eisenger, "Control Sharing in the City," American Behavioral Scientist, Vol. 15, N.o 1 (September/October 1971). pp. $36-51$.

79. Jason Epstein, "The Politics of Black Separatism," Currrent, N.0 98 (August 1968), pp. 26-32.

80. John L. Erlich and John E. Tropman, "The Politcs of Participation: Student Power," Soclal Work, Vol. 14 (October 1969), pp. 64-72.

81. Suzanne Farkas, "The Federal Role in Urban Decentralization," American Behavioral Scientist, Vol. 15, N.0 1 (SeptemVer/October 1971), pp. 15-35.

82. Richard Flacks, "On the Uses of Participatory Democracy," Dissent, Vol. 13 (November/December 1966), pp. 701-708.

83. E. Freedman, "Citizen Participation: A Training Tool for Leadership," Public Management Vol. 51, N. ${ }^{0} 7$ (July 1969).

84. H. Paul Friesema, "Black Control of Central Cities: The Hollow Prize," Journal of the American Institute of Planners, Vol. XXXV (March 1969), pp. 75-79.
85. James P. Gannon, "Tough Teachers: Decentralization Clash in New York Underlines School Union's Militancy," Wall Street Journal (December 20, 1968).

86. Herbert J. Gans, "Toward the Equality Revolution," Current, N.0 102, December 1968, pp. 6-14.

87. Marilyn Gittell, Participants and Participation (New York: Praeger, 1968).

88. Politics of Urban Education (New York: Praeger, 1969).

89. "Urban School Politics: Professionalism vs. Reform," Journal of Social Issues, Vol. XXVI, N.० 3 (Summer 1970), pp. 69-84.

90. Nathan Glaser, "For White and Black, Community Control is the Issue," The New York Times Magazine, April 27, 1969, pp. $36 \mathrm{ff}$.

91. William R. Grant, "Community Control vs. School Integration - The Case of Detroit," The Public Interest, N.0 24 (Summer 1971), pp. 62-79.

92. Donald Haider, "The Political Economy of Decentralization," American Behavioral Scientist, Vol. 15, N. ${ }^{0} 1$ (September/October 1971). pp. 108-129.

93. Howard W. Hallman Community Corporations and Neighborhood Control: Case Studies of Community Corporations and Neighborhood Boards (New York: Praeger, 1970)

94. Management." Public Management, Vol. 53. N.० 1 (January 1971), pp. 3-6.

95. Herbert H. Hyman, "Planning Via Citizens: Two Styles," Journal of the American Institute of Planners, Vol. 35 (March 1969), pp. $105-112$.

96. Richard Karp, "School Decentralization in New York: A Case Study," Interplay (August/September 1968), pp. 9-14.

97. Herbert Kaufman, "Administration, Decentralization, and Political Power," Public Administration Review, Vol. XXIX, N. ${ }^{0} 1$ (January/February 1969), pp. 3-15.

98. Alexander Klein, "Toward Participatory Citizenship," Current, N.0 121 (September 1970), pp. 3-11.

99. Milton Kotler, Neighborhood Government: The Local Foundations of Pollitical Life (New York: Bobbs-Merrill, 1969).

100. Ralph M. Kramer, Participation of the Poor (Englewood Cliffs, N.J.: PrerticeHall, 1969). 
101. Irving Kristol, "The End of Liberalism?" Current, N.॰ 103 (January 1969), pp. 6-15.

102. , "Decentralization for What?" Public Interest, N.0 11 (Spring 1968), pp. 17-25.

103. Michael Lipsky, "Street-Level Bureaucracy and the Analysis of Urban Reform," Urban Affairs Quarterly, Vol. 6, N. ${ }^{\circ} 4$ (June 1971), pp. 391-409.

104. Rensis Likert, New Patterns of Manage. ment (New York: McGraw-Hill Book Company, 1961).

105. John D. C. Little, et al., "Citizen Feedlock System: The Puerto Rico Model," National Civic Review, Vol. 60, N.0 4 (April 1971), pp. 191-198 and 203.

106. Edward R. Lowenstein, "Citizen Participation and The Administrative Agency in Urban Development: Some Problems and Proposals," The Social Service Review, Vol. 45, N.o 3 (September 1971), pp. 289-301.

107. Theodore Lowi, "The Public Philosophy: Interest Group Liberalism," American Political Science Review, Vol. LXI (March 1967), pp. 4-24.

108. Ritchie P. Lowry, "Power to the People Political Evolution or Revolution," Urban and Social Change Review, Vol. $3, N^{\circ}{ }^{\circ} 2$ (Spring 1970), pp. 2-6.

109. Staughton Lynd, "The New Radicals and Participatory Democracy," Dissent, Vol. XII (Summer 1965), pp. 324-333.

110. Douglas McGregor, The Human Side of Enterprise (New York: McGraw Hill, 1960).

111. Dale Rogers Marshall, "Public Participation and the Politics of Poverty," in Peter Orleans and William R. Ellis, Jr. (eds.), Race, Change and Urban Society, Urban Affairs Annual Review, N.o 5 (Beverly Hills, Calif.: Sage Publications, 1971), pp. $451-482$.

112. V. Mathews, "Citizen Participation; An Analytical Study of the Literature," (Washington, D.C.: U.S. Department of Jus. tice, Community Relations Service, June 1968).

113. Lester W. Milbrath, Political Participation: How and Why Do People Get Involved in Politics (Chicago: Rand McNally, 1965).

114. S.M. Miller, and Martin Rein, "Participation, Poverty, and Administration," Public Administration Review, Vol. XXIX, N. ${ }^{0} 1$ (January/February 1969), pp. 15-25.

115. Melvin B. Mogulof, "Citizen Participation: A Review and Commentary on Federal Policies and Practices" (Washington, D.C.: The Urban Institute, 1970), mimeo.
116. "Coalition to Adversary: Citien Participation in Three Federal Programs," Journal of the American Institute of Planners, Vol. 35 (July 1969), pp. 225-232.

117. Daniel P. Moynihan, Maximum Feasible Misunderstanding (New York: Free Press, 1969).

118. Carol Pateman, Participation and Demomocratic Theory (Cambridge: Cambridge University Press, 1970).

119. Paul E. Peterson, "Forms of Representation: Participation of the Poor in the Community Action Program," American Political Science Review, Vol. LXIV, N. 2 (June 1970), pp. 491-507.

120. Frank Riessman and Alan Cartner, "Community Control and Radical Social Change," Social Policy (May/June 1970), pp. 52-55.

121. Wallace Roberts, "The Battle for Urban Schools," Saturday Review (November 16, 1968), pp. 97-99, 117.

122. William Ryan, Blaming the Victim (NeW York: Pantheon Books, 1971).

123. William G. Scott, "Organization Government: Prospects for a Truly Participativo System," Public Administration Review, Vol. XXIX, N.O 1, (January/February 1969), pp. $43-53$.

124. Henry Schmandt, "Decentralization: A Structural Imperative," (Washington, D.C. Center for Governmental Studies), mimeo.

125. David H. Smith and Richard F. MCGrail, "Community Control of Schools: A. Review of Issues and Option," Urban 1969), Social Change Review, Vol. 3 (Fall 1969) pp. 2-9.

126. Michael P. Smith, "Self-Fulfillment in a Bureaucratic Society: A Commentary on the Thought of Gabriel Marcel," Pub N. ${ }^{0} 1$ Administration Review, Vol. XXIX, (January/February 1969), pp. 25-32.

127. Hans Spiegel, Citizen Participation in Urban Development: Concepts and issues, Vol. 1 (Washington, D.C.: NTL Institut for Applied Behavioral Science, 1968).

128. James Turner, "Blacks in the Cities: Land and Self Determination," The Black Scho lar, Vol. 1 (April 1970), pp. 9-13.

129. Jon Van Til and Sally Bould Van Til, "Citizen Participation in Social Policys. The End of the Cycie," Social Probl3-323. 
130.

in Social Policy: The End of the Cycle?" Social Problems, Vol. 17, N.o 3 (Winter 1970), pp. 313-323.

131. Herbert G. Wilcox "Hierarchy, Human Nature, and the Participative Panacea," Public Administration Review, Vol. XXIX, N. 01 (January/February 1969), pp. 53-63.

132. Charles E. Wilson, "Year One at I. S. 201," Social Policy (May/June 1970), pp. 10-17.

133. George D. Younger, "Education Crisis: New York Style," Christianity and Crisis, Vol. 28 (December 23, 1968), pp. 312317.

134. Louis A. Zurcher, Jr., "The Poverty Boards: Some Consequences of Maximum Feasible Participation," Journal of Social Issues, Vol. XXVI, N.o 3 (Summer 1970).

\section{A Nova Administraçăo Pública}

135. Robert A. Biller, "Some Implications of Adaptation Capacity for Organizational and Political Development," in Frank Marini (ed.), Toward A New Administration: The Minnowbrook Perspective (Scranton: Chandler Publishing Co, 1971), pp. 93-121.

136.

of , "The Changing Political Context of Urban Administration," Public Management, Vol. 53, N. 11 (November 1971). pp. 5-8.

137.

Stephen R. Chitwood and Michael M. Harmon, "New Public Administration, Humanism, and Organizational Behavior," Public Management, Vol. 53, N.o 11 (November 1971), pp. 9-12.

138. Ross Clayton and Ron Gilbert, "Perspectives of Public Managers: Their Implications for Public Service Delivery Systems," Public Management, Vol. 53, N.O 11 (November 1971), Pp. 9-12.

139. Matthew A. Crenson, Comment: "Contract, Love, and Character Building," in Frank Marini (ed.), Toward A New Public Administration: The Minnowbrook Perspective (Scranton: Chandler Publishing Co., 1971), pp. 83-89.

140.

H. George Frederickson, "Creating Tomorrow's Public Administration," Public Management, Vol. 53, N.o 11 (Nóvember 1971), pp. 2-4.

141.

Dommorow's Organization: What Does It Mean To Public Administration?" Public Management, Vol. 53, N. 07 (July 1971), pp. 22-25.
142. Michael M. Harmon, "Normative Theory and Public Administration: Some Suggestions for a Redefinition of Administrative Responsibility," in Frank Marini (ed!. Toward A New Public Administration: The Minnowbrook Perspective (Scranton: Chandler Publishing Co., 1971), pp. 172-185.

143. Larry Kirkhart, "Toward a Theory of Public Administration," in Frank Marini (ed.), Toward A New Public Administration: The Minnowbrook Perspective (Scranton: Chandler Publishing Co., 1971), pp. 127-164.

144. Todd R. La Porte, "The Recovery of Relevance in the Study of Public Organization," in Frank Marini (ed.), Toward A New Public Administration: The Minnowbrook Perspective (Scranton: Chandler Publishing Co., 1971), pp. 17-48.

145. Frank Marini (ed.), Toward A New Public Administration: The Minnowbrook Perspective (Scranton: Chandler Publishing Co., 1971).

146. Carleton Sharpe, "Reaction to the New Public Administration," Public Management, Vol. 53, N. 11 (November 1971), pp. 14-15.

147. William B. Storm, "Normative Possibilities for Tomorrow's Public Administration," paper presented at the National Conference of the American Society for Public Administration, Denver, Colorado, April 1971.

148. Dwight Waldo, "Public Administration in a Time of Revolution," Public Administration Review, Vol. XXVIII, N.0 4, (July/ August 1968), pp. 362-368.

149. Orion F. White, Jr., "Social Change and Administration Adaptation," in Frank Marini (ed.), Toward A New Administration: The Minnowbrook Perspective (Scranton: Chandler Publishing Co., 1971), pp. 59-83.

150. Robert F. Wilcox "The New Public Administration: Have Things Really Changed That Much?" Public Management, Vol. 53,5 (May 1971) pp. 25-28.

\section{Simpósios sobre Administraçăo • Participaçăo} (1968-71)

151. "Urban Decentralization and Community Participation," American Behavioral Scientist, Vol. 15, N.0 1 (September/October 1971).

152. "Alienation, Decentralization, and Participation," Public Administration Review, Vol. XXIX, N. 1 (January/February 1969). 
153. "Participatory Democracy," The Urban and Social Change Review, Vol. 3, N. ${ }^{\circ} 2$ (Spring 1970).

154. "Neighborhood Management," Public Management, Vol. 53, N. ${ }^{\circ} 1$ (January 1971).

155. "Community Control of Schools," The Urban and Social Change Review, Vol. 3 , N.o 1 (Fall 1969).

156. "The New P. A.," Public Management, Vol. 53, N. ${ }^{\circ} 11$ (November 1971).

157. "The American City Manager: An Urban Administrator in a Complex and Evolving Situation," Public Administration Review, Vol. XXXI, N.0 1 (January/February 1971).

158. "Management Trends," Public Management, Vol. 53, N.0 3 (March 1971).

159. "Does Structure Count?" Public Management, Vol. 53, N. 07 (July 1971).

160. "Local Government Careers-Keeping the Options Opean," Public Management, Vol. 53, N.o 5 (May 1971).
161. Collective Negotiations in the Public Service," Public Administration Review, Vol. XXVIII, N.0 2 (March/April 1968).

162. "Towards an International Civil Service." Public Administration Review, Vol. $X X X$, N. ${ }^{\circ} 3$ (May/June 1970).

163. "Collective Negotiations in the Public Service," Public Administration Review, Vol. XXVIII, N. 2 (March/April 1968).

164. "Collective Bargaining in the Public Ser" vice: A Reappraisal," Public Administra: tion Review, Vol. XXXII, N. ${ }^{\circ} 2$ (March/ April 1972).

165. "Neighborhoods and Citizen Involve:" ment," Public Administration Review,' Vol. XXXII, N.O 3 (May/June 1972).

166. "Citizens Action in Model Cities and CAP Programs: Case Studies and Evaluation." Public Administration Review, Vol. XXXII, Special Issue (September 1972). 